\title{
A multistate epidemic outbreak of Salmonella Goldcoast infection in humans, June 2009 to March 2010: the investigation in Italy
}

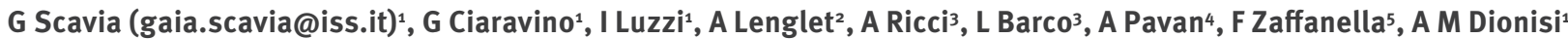

1. Istituto Superiore di Sanitá, Rome, Italy

2. European Centre for Disease Prevention and Control (ECDC), Stockholm, Sweden

3. Istituto Zooprofilattico Sperimentale delle Venezie, Padua, Italy

4. Regione Lombardia, Milan, Italy

5. Azienda Sanitaria Locale della provincia di Mantova, Mantova, Italy

After an urgent inquiry into a suspected international outbreak of Salmonella Goldcoast infection was launched by Hungary in October 2009 a nationwide multidisciplinary investigation was carried out in Italy. The aims were to verify whether the higher than expected number of cases of $S$. Goldcoast infection that had occurred in Italy in the previous months were linked to the outbreak in Hungary and to determine their origin. Between June 2009 and March 2010, 79 confirmed cases of $S$. Goldcoast infection were identified. Of these, 17 were part of three different point-source outbreaks probably associated with the consumption of salami. Eating salami was also reported by 20 of the 39 sporadic cases that could be interviewed. Fifteen strains of $S$. Goldcoast isolated from the cases were typed by pulsed-field gel electrophoresis. They shared more than $90 \%$ homology with the Hungarian epidemic strain and were also highly similar to $S$. Goldcoast strains that had been isolated in Italy from pigs and pork-containing food items in 2009 and 2010. Although the origin of the outbreak and the common source linking the Hungarian and the Italian cases could not be definitively identified, our results suggest a possible zoonotic connection of the outbreak cases with the pork production chain.

\section{Introduction}

Salmonella enterica serotype Goldcoast is a pathogen of zoonotic origin which causes clinical disease in humans, primarily acute gastrointestinal illness (AGI). S. Goldcoast infection in humans is rare and is usually acquired through the consumption of raw or undercooked food of animal origin. Although most S. Goldcoast infections are reported as sporadic cases, a few epidemic outbreaks have been described in the international literature [1-4]. In 2005 an outbreak of S. Goldcoast infection involved tourists from the United Kingdom (UK), Ireland, Denmark, Norway and Sweden who had travelled to Spain, but could not be linked to any specific source [2]. In 2001, at least nine people in Germany became infected due to the consumption of fermented sausages of pork origin [1]. The specific association of this Salmonella serovar with swine emerged also from the baseline surveys on the prevalence of Salmonella spp. in different food-producing animals in the European Union (EU) [5-8]. Compared with other Salmonella serovars that have been shown to occur in many animals species and categories already surveyed in the EU (hens, broilers and turkeys), S. Goldcoast was the only serovar exclusively associated with pigs [9]. $S$. Goldcoast has also been reported as one of the most common Salmonella serovars identified from cattle in Germany, the United Kingdom (UK) and Spain in 2007 and $2008[10,11]$.

In Italy, besides the national official surveillance system for human cases of Salmonella spp. infections based on the identification of clinical illness, the laboratory-based surveillance network for enteric pathogens Enter-net Italia (www.iss.it/ente) provides information on the microbiological characteristics of Salmonella spp. strains isolated from humans [12]. The data are gathered through a network of regional reference laboratories which characterise the strains isolated from the peripheral diagnostic laboratories. It is important to mention that due to a certain local variability of the number of peripheral laboratories and their compliance to surveillance, the sensitivity of the Enter-net Italia may differ between Italian regions, as a recent paper has shown for some regions of northern Italy [13].

The Enter-net Italia network is coordinated by the National Reference Laboratory for Salmonella infection in humans at the Istituto Superiore di Sanità (ISS). It is strictly interfaced with the homologous Enter-Vet 
surveillance network for food and animals, coordinated by the Veterinary National Reference Laboratory for Salmonella at the Istituto Zooprofilattico Sperimentale delle Venezie, with whom they share protocols and databases [12].

On 7 October 2009, Hungary launched an urgent inquiry through the Food- and Waterborne Diseases and Zoonoses Network (FWD network), which is coordinated by the European Centre for Disease Prevention and Control $(E C D C)$, reporting an unusual increase in S. Goldcoast human infections in the country. The Enter-net Italia database indicated that a higher than expected number of $S$. Goldocoast isolates, clustering in time and in space at regional level, had occurred also in Italy, particularly since June 2009. Moreover, the molecular characteristics of the $S$. Goldcoast strains isolated from the case-patients, analysed by pulsedfield gel electrophoresis (PFGE), showed a genetic similarity of more than $90 \%$ with those from Hungary. Since Spain, Denmark, Norway, and the UK had also reported a higher than expected number of cases of S.Goldcoast infection in the same period (personal communication Celine Gossner, 8 December 2009), it was hypothesised that the Italian cases could be part of a larger multistate outbreak. In this article we report the results of the investigation carried out in Italy with the aim of identifying the origin of the Italian cluster of $S$. Goldcoast cases and the possible epidemiological link with cases that occurred in other EU Member States.

\section{Methods}

To coordinate the investigation activities, a multidisciplinary team was set up in November 2009 including the coordinators of the Enter-net and Enter-Vet surveillance networks, the health authorities of those regions where human cases had been passively reported, and the veterinary regional laboratories. Active case finding was carried out by sending an alert to the official health authorities of all the Italian regions requesting information on any further laboratory-confirmed cases of $S$. Goldcoast infection that had occurred in 2009. The same alert was sent to the Enter-Vet network in order to obtain information about the origin and the characteristics of any S. Goldcoast strains isolated from animals and food in the last five years.

\section{Epidemiological investigation}

The following definition of a $S$. Goldcoast epidemic case was adopted: a person who had a confirmed laboratory diagnosis of $S$. Goldcoast in Italy, after 1 June 2009. This date was chosen because a higher than expected number of cases was reported starting from 1 June. Patients fulfilling these criteria were traced and interviewed, upon consent, using a standardised questionnaire. For patients younger than 18 years the interview was conducted with the parents. The questionnaire was based on one designed by ECDC for the $S$. Goldcoast multistate outbreak investigation, and modified to better fit the Italian context (especially concerning food exposures). We collected information on the clinical course of AGI associated with S. Goldcoast infection, food consumption, contact with other people reporting AGI symptoms and contact with animals, in the week before the onset of symptoms. The cases were also asked about recent travel abroad. Cases who had already been interviewed by the local health authority were not interviewed again.

Cases were categorised as clustered or sporadic cases depending on whether a clear epidemiological link with other $S$. Goldcoast cases in Italy could be established. An epidemiological link included persons that attended the same social event as a confirmed case or those living with a household member with a confirmed S. Goldcoast infection.

A descriptive study was conducted with the sporadic cases in order to describe the travel and food consumption history as well as contacts with animals or people with AGI, in the week before the onset of illness. To investigate a single point-source outbreak that occurred on 9 June 2009 associated with S. Goldcoast infection, a cohort study was performed aimed at detecting the association between the consumption of food and the occurrence of AGI. Overall, the cohort study included 34 people, resident in the Lombardia region, who had participated in a day trip to Tuscany, and provided information on food consumption. The following case definition for AGI was adopted: a person who developed diarrhoea or had a positive culture for S. Goldcoast within seven days after the trip to Tuscany. For every food item, specific attack rates in exposed and unexposed individuals were calculated. The food-specific risk ratio (RR) with $95 \%$ confidence intervals $(\mathrm{Cl})$ and $\mathrm{p}$ values were calculated by univariate analysis, with being or not an AGI-case as the outcome variable and the consumption of each food item as the explanatory variable.

\section{Microbiological and molecular investigation}

S. Goldcoast human isolates from case-patients reported since 1 June 2009 were sent to ISS for serotyping confirmation, antibiotic resistance testing and molecular characterisation by PFGE. The antimicrobial resistance was assessed by the disk diffusion method using the Enter-net reference panel [14] which includes 12 antibiotic disks (Becton Dickinson).

The PFGE analysis was performed according to the PulseNet standardised protocol [15] using Xbal as the restriction enzyme (New England Biolabs, Ipswich, $M A)$. To avoid degradation of DNA samples $50 \mu \mathrm{M}$ thiourea was added to the running buffer and agarose gel [16]. S. enterica serotype Braenderup H9812 strain was used as the molecular size marker [17].

Dendrogram and cluster analysis were performed using algorithms available in the BioNumerics software package v.6.o (Applied Maths, Sint-MartensLatem, Belgium). Per cent similarity between different 
Geographical distribution, by place of residence, of Salmonella Goldcoast case-patients, Italy, 1 June 2009 to 31 March 2010 $(n=76)$

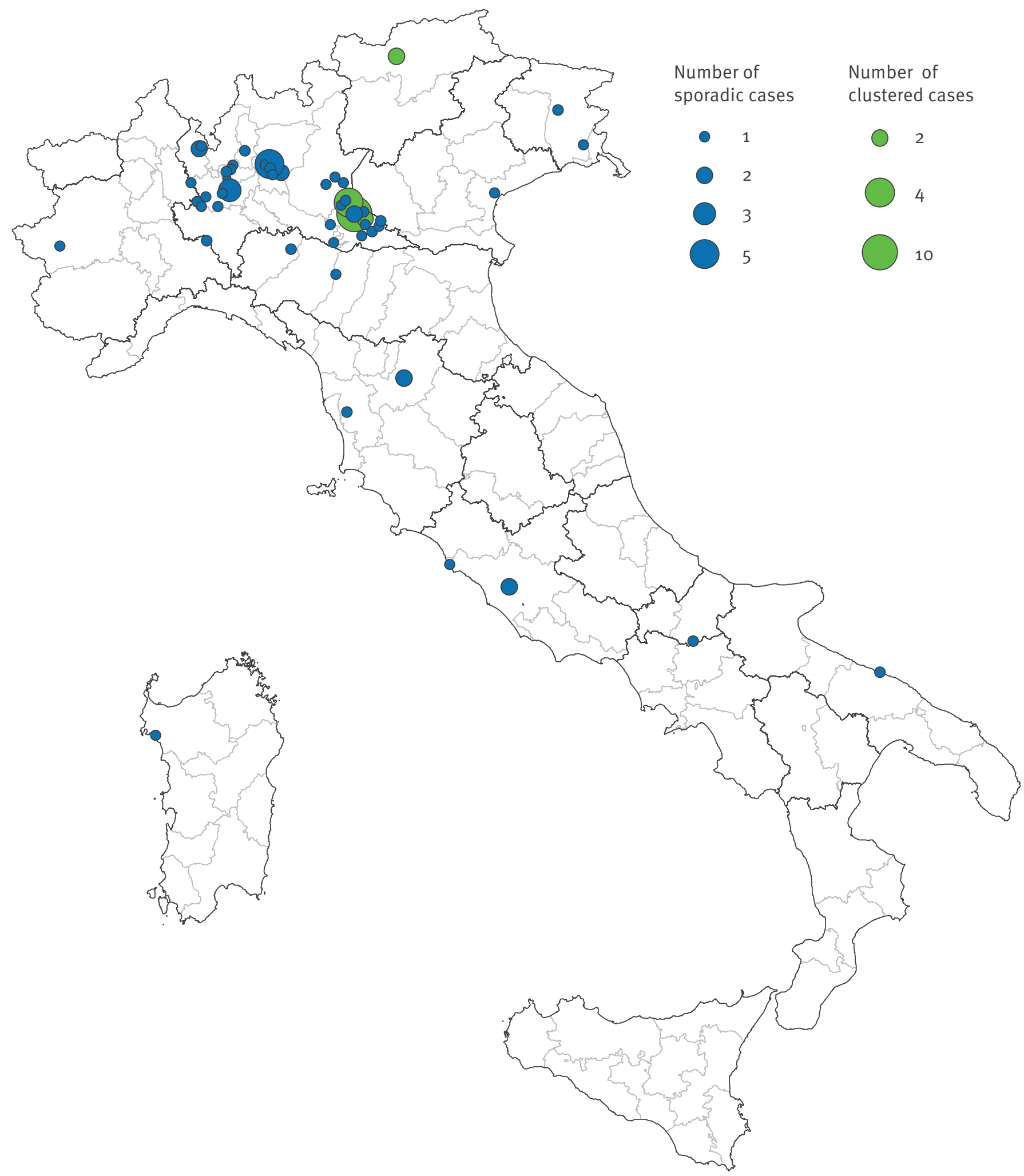

For three cases the place of residence was unavailable. 
chromosomal fingerprints was scored by the Dice coefficient. The unweighted pair group method with arithmetic means (UPGMA), with a $1.00 \%$ tolerance limit and $1.00 \%$ optimisation, was used to obtain the dendrogram. DNA profiles differing by one or more DNA fragments were considered as distinct patterns. Strains with a coefficient of similarity of at least $90 \%$ were considered as genetically closely related. S. Goldcoast strains isolated in 2009 from the pig production chain and one PFGE profile from an isolate belonging to the Hungarian outbreak were also included in the cluster analysis.

\section{Results}

Between 1 June 2009 and 31 March 2010, a total of 79 $S$. Goldcoast cases were identified across Italy. The majority of them $(n=60)$ were reported from northern Italy, particularly the Lombardia region (Figure 1), with the remaining cases affecting 10 additional regions (Italy has 20 regions in total). More cases were male $(n=48)$ than female $(n=31)$, and more cases were adults of at least 18 years of age $(n=56)$ than children under the age of 18 years $(n=23)$. The median age of casepatients was 50 years (range: 10 months-93 years).

The distribution of the cases by week of onset of symptoms (Figure 2) showed that cases peaked in week 23 (June 2009), which coincided with the time of the outbreak related to the trip to Tuscany. Sixty-two cases had no apparent link with other cases with a laboratory-confirmed diagnosis of $S$. Goldcoast and were classified as sporadic cases. In the following, these are described separately from the remaining 17 cases that were part of three different clusters.

\section{The sporadic cases of $S$. Goldcoast infection}

The investigation of sporadic cases took place between 1 December 2009 and 31 March 2010. The questionnaire on clinical symptoms associated with S. Goldcoast infection and exposures to potential sources of infection could be administered only to 39 of the 62 sporadic cases. In 22 cases the interview could not be completed due to one of the following reasons: refusal to participate, death, failure to trace the patient or reporting date after 31 March 2010. One case who had been interviewed was later excluded from the analysis because the information had been provided by a relative of the patient.

Thirty-seven of the 39 interviewed cases reported clinical symptoms. These included watery diarrhoea, abdominal cramps, fever, fatigue, vomiting and nausea (Table 1). The duration of illness ranged between two and 20 days (mean: $7 \pm 5.2$ days; median: 5 days). Sixteen cases were hospitalised. Two patients (66 and 77 years of age) with underlying chronic disease, died following the $S$. Goldcoast infection.

In the seven-day period before the onset of symptoms 15 cases reported exposure to risk factors for $S$. Goldcoast infection not related with food-consumption: travelling abroad $(n=2)$, visiting farms $(n=2)$, and contact with companion animals $(n=11)$, poultry $(n=6)$ or food-producing animals (cattle) $(n=1)$. Contact with household members with gastrointestinal symptoms in

\section{FIGURE 2}

Distribution, by week of onset of symptoms, of Salmonella Goldcoast case-patients, Italy, 1 January 2009 to 31 March 2010 $(\mathrm{n}=83)$

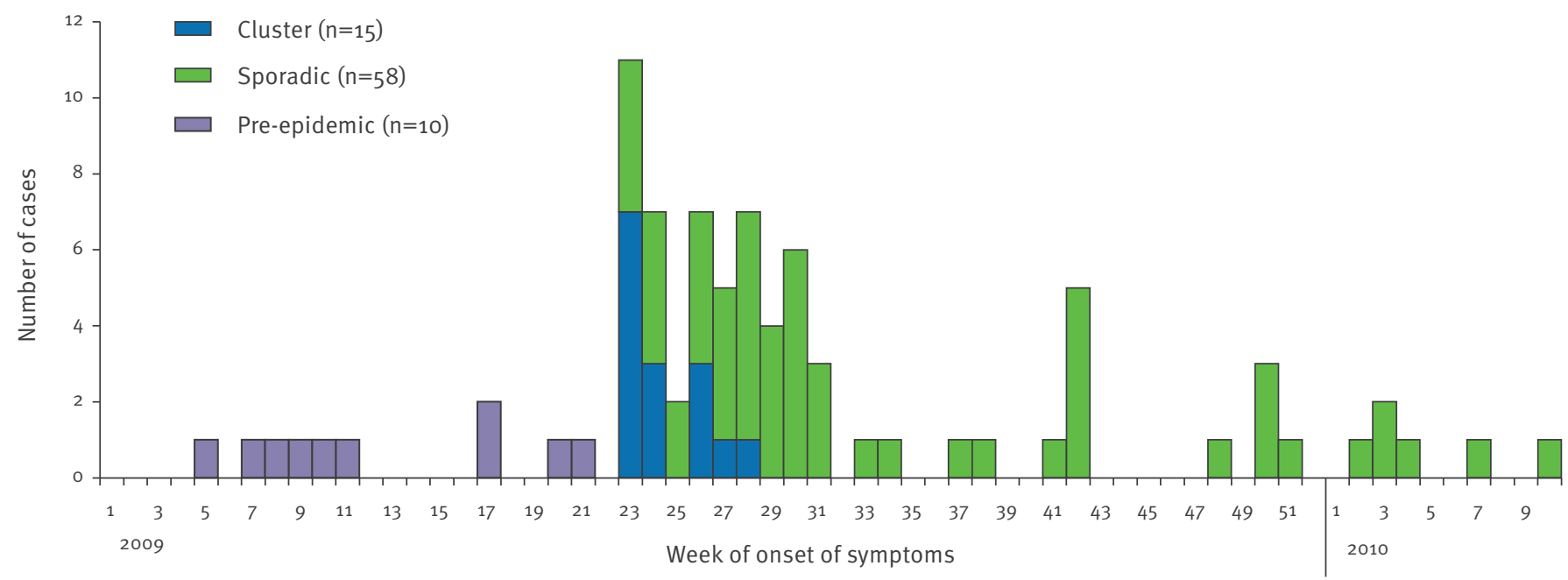

Purple boxes refer to pre-epidemic cases, blue and green boxes refer to outbreak cases.

Two cases in the cluster and four sporadic cases were asymptomatic and are not shown in the figure. 
Frequency and duration of clinical symptoms reported by sporadic Salmonella Goldocoast case-patients, Italy, 1 June 2009 to 31 March $2010(n=37)$

\begin{tabular}{|l|c|c|c|c|}
\hline \multirow{2}{*}{ Symptom } & $\begin{array}{c}\text { S. Goldcoast cases reporting } \\
\text { the clinical symptoms }\end{array}$ & $\begin{array}{c}\text { Cases who answered the } \\
\text { question on the symptom }\end{array}$ & Range (days) & Mean (days) \\
\hline Watery diarrhoea & 28 & 33 & $2-20$ & 6 \\
\hline Bloody diarrhoea & 4 & 33 & $1-10$ & 4 \\
\hline Abdominal cramps & 25 & 33 & $1-20$ & 6 \\
\hline Fever & 22 & 33 & $1-10$ & 3 \\
\hline Fatigue & 21 & 31 & $1-20$ & 7 \\
\hline Vomiting & 16 & 33 & $1-6$ & 2 \\
\hline Nausea & 13 & 33 & $1-5$ & 3 \\
\hline Headache & 8 & 32 & $1-10$ & \\
\hline Body ache & 6 & 30 & & 3 \\
\hline
\end{tabular}

the seven days before the onset of illness was reported from six patients. The description of food items consumed in the week before the onset of AGI symptoms is reported in Table 2.

\section{Microbiological investigation}

During the period from June 2009 to February 2010, 15 $S$. Goldcoast strains from human sporadic cases were received at ISS. Nine were from cases that occurred in northern Italy, five were from central Italy and one from southern Italy. All of them were confirmed as S. Goldcoast with specific antisera and susceptible to all drugs tested, when tested for antimicrobial susceptibility.

All but three strains were typeable by PFGE. Cluster analysis was performed including PFGE profiles of 12 Italian human outbreak strains, one isolate from a Hungarian case, representative of 43 strains with identical PFGE pattern isolated from patients involved in the outbreak, five strains isolated in Italy from food (pork minced meat, pork sausages and fish), and one from rendered animal proteins of pork and beef origin.

The cluster analysis of the PFGE profiles revealed that all the strains of human and animal origin had a high genetic homology ( $\geq 90 \%)$ with the Hungarian representative strain.

\section{The clustered cases}

Three different clusters of S. Goldcoast infections, all from the same area of the Lombardia region, could be identified. The largest cluster included 11 cases from the same town, who had participated in a day trip to Tuscany in early June 2009. Of the whole group of participants, 34 persons ( 21 female and 13 male) could be traced and interviewed about the occurrence of symptoms and food items consumed in the restaurant where the group had had lunch, as well as food they had brought from home. The median age of the respondents was 61 years (range: 3-91 years). A total of 19 people (all but one older than 18 years) reported AGI symptoms, which included watery diarrhoea $(n=19)$, fever $(n=12)$, vomiting $(n=6)$ and abdominal pain $(n=10)$. Of those, one patient needed hospitalisation. The mean incubation time was $30 \pm 19$ hours (median: 23 hours; range: $12 \neg-64$ hours). Fifteen patients submitted stool samples for laboratory investigation, from which $S$. Goldcoast was isolated in 11 cases.

Eating a sandwich with a traditional salami (Salame Mantovano) taken from home was the only item with a statistically significant association with AGI (RR: 1.98; $p=0.048)$. AGI occurred in 14 of 20 people reporting and in five of 14 people not reporting consumption of salami. The salami sandwiches had been prepared at home by some of the participants, using various types of Salame Mantovano (including both commercial and home-made products), all purchased or produced for domestic consumption in the Mantova province.

The second cluster involved a family and was also linked to the consumption of a salami. S. Goldcoast was isolated from all four members of the family (both parents and their teenage children) resident in a village located $10 \mathrm{~km}$ from the place of residence of the cases in the first cluster. The family members showed AGI symptoms in early July 2009, two days after having eaten a Salame Mantovano purchased from a local retailer. The food trace-back showed that two different brands of Salami Mantovano had been sold in the supermarket. They were manufactured by two different factories located in the province of Mantova.

The third cluster included an adult and teenage child, both resident outside the Lombardia region, who had 
Food consumed in the seven days before the onset of clinical symptoms by sporadic Salmonella Goldcoast case-patients, Italy, 1 June 2009 to 31 March $2010(n=37)$

\begin{tabular}{|l|c|c|}
\hline Food & $\begin{array}{c}\text { S. Goldcoast cases reporting the } \\
\text { consumption of the food item }\end{array}$ & $\begin{array}{c}\text { S. Goldcoast cases who answered the } \\
\text { question on the food item }\end{array}$ \\
\hline Pork-containing food items & 25 & 36 \\
\hline Cooked ham & 27 & 37 \\
\hline Dry-cured ham & 20 & 37 \\
\hline Salami & 11 & 36 \\
\hline Bacon & 10 & 34 \\
\hline Sausages & 8 & 32 \\
\hline Frankfurter sausages & 3 & \\
\hline Other pork- containing food & & \\
\hline Meat & 28 & 33 \\
\hline Beef & 7 & \\
\hline Pork & & \\
\hline Dairy & 23 & \\
\hline Matured cheese & 24 & \\
\hline Cream cheese & 0 & \\
\hline Raw milk & & \\
\hline
\end{tabular}

travelled at the beginning of July 2009 to Mantova province, where they had consumed a sandwich with Salame Mantovano in a bar. The adult showed clinical symptoms of AGI two days later and was positive in culture for S. Goldcoast. The child also tested positive for $S$. Goldcoast but did not have any clinical symptoms.

Investigation of food and the food chain Due to a delay of more than four months between the occurrence of cases and the $S$. Goldcoast outbreak investigation, specimen of the suspected food could not be collected and examined for S. Goldcoast. Even for the cluster on the trip to Tuscany, which was promptly investigated after it was reported, neither leftover food nor samples of the same batches of salami could be taken and tested for $S$. Goldcoast, since the preliminary investigation omitted to include in the analytical study any food taken from home but focused on the food items consumed in the restaurant.

Data for S. Goldcoast from the Enter-Vet database indicated that six strains had been isolated in 2009 in Italy from food and matrices of animal origin, mostly from the pork food chain. In particular the isolates were obtained from various batches of pork minced meat $(n=2)$ and pork sausages $(n=2)$, sampled in different cutting and manufacturing plants in northern and central Italy, from a sample of rendered animal protein of pork and beef origin intended for use as agricultural fertiliser, sampled in a rendering plant, and from a sample of fish organs. These last two sources were the only ones sampled in Mantova province. All isolates but one had been sampled between 10 June and 28 October 2009, whenever most human cases were observed. Trace-back of the $S$. Goldcoast strains isolated from the pork minced meat led to a single pig farm, located in Lombardia region, that raised pigs only for the fattening production-cycle. No further trace-back was possible for the other isolates.

Overall 28 of the 31 strains of S. Goldcoast of animal origin isolated in Italy between 2007 and 2009, were sampled along the pig production chain either at farm level $(n=4)$, slaughterhouse $(n=10)$, rendering plant $(n=1)$, or in the post-harvest production chain such as processing plants $(n=2)$, salami factories $(n=10)$ and retail $(n=1)$. Of the $S$. Goldcoast strains isolated in the post-harvest stage, six were from ground raw pork meat and four were from finished salami at different points in the curing process.

Unfortunately details on the reasons for sampling were not available, except for the $S$. Goldcoast strains from farms and slaughterers that had been sampled in 2007 and 2008 in the context of the EU baseline surveys on the prevalence on Salmonella spp. in slaughter and in breeding pigs, respectively $[8,9]$.

\section{Discussion}

Our investigation revealed that a community-wide outbreak of $S$. Goldcoast probably associated with a continuous source of infection occurred in Italy between 2009 and 2010. It cannot be excluded that the real burden of this outbreak and its geographical distribution 
Cluster analysis of Salmonella Goldcoast strains of human and animal origin, Italy, June 2009-March 2010 (n=19)

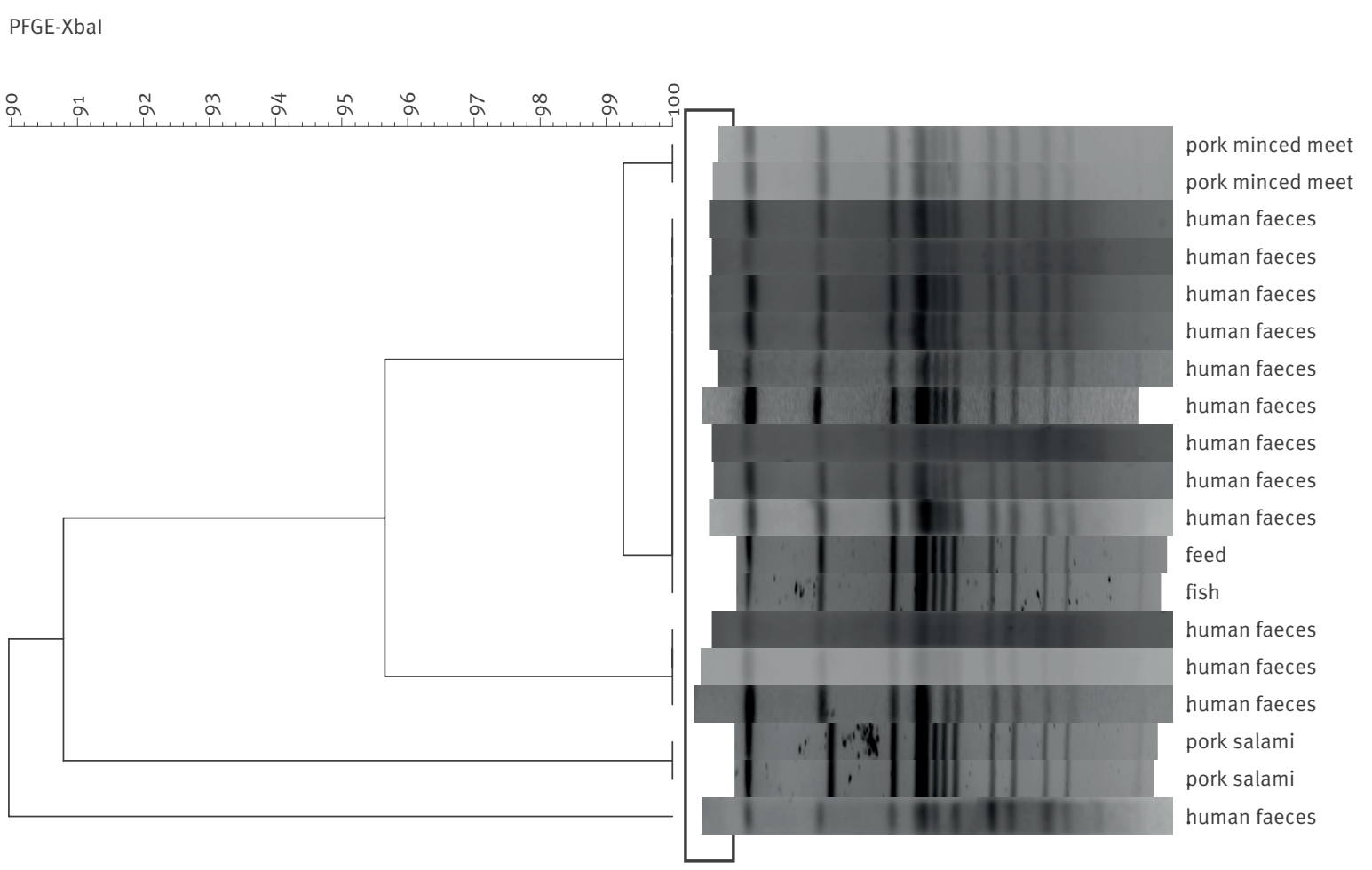

$\begin{array}{ll}2009 & \text { IT } \\ 2009 & \text { IT } \\ 2009 & \text { IT } \\ 2009 & \text { IT } \\ 2009 & \text { IT } \\ 2009 & \text { IT } \\ 2010 & \text { IT } \\ 2009 & \text { HUN } \\ 2009 & \text { IT } \\ 2009 & \text { IT } \\ 2009 & \text { IT } \\ 2009 & \text { IT } \\ 2009 & \text { IT } \\ 2009 & \text { IT } \\ 2009 & \text { IT } \\ 2010 & \text { IT } \\ 2009 & \text { IT } \\ 2009 & \text { IT } \\ 2010 & \text { IT }\end{array}$

Human strains include isolates from 12 Italian cases and one Hungarian case. Strains of animal origin include isolates from pork minced meat $(n=2)$, pork sausage $(n=2)$, rendered animal protein $(n=1)$ and fish $(n=1)$ isolated in Italy in 2009 and 2010 .

were wider than what was identified. Possible reasons for that include a general tendency to submit only a small proportion of stool samples for diagnostic investigation in patients with AGI [18], especially when they are characterised by mild symptoms, and the heterogeneous availability of typing methods for Salmonella spp. in peripheral laboratories across the country. During the study period, the majority of cases were reported from the Lombardia region. This region has a well-established surveillance system for enteric pathogens causing AGI, including Salmonella spp., which is more sensitive than systems in other Italian regions [13]. It can therefore be argued that the outbreak may not have been limited to Lombardia, but that other epidemic cases may have occurred elsewhere in the country and remained undetected and/or unreported.

The consumption of pork-containing products has previously been described as associated with $S$. Goldcoast outbreaks. Our investigation therefore concentrated on the possibility that pork-containing products could be the main cause of this outbreak. This hypothesis was strongly supported by the investigation in food and animals, which indicated a close relationship between
S. Goldcoast and the pork production chain, and by the microbiological characterisation of the $S$. Goldcoast strains, including PFGE typing, which showed a high genetic homology ( $\geq 99 \%)$ between strains of human and pig origin.

Epidemiological and microbiological results failed to implicate a definitive source of the outbreak. Nonetheless the consumption of different types of pork-containing food, in particular salami remains a very possible source, as it was frequently reported by the sporadic cases and also emerged from the investigation of all three clusters of $S$. Goldcoast infection. Besides dry cured and cooked ham, which are considered products with a low-risk of Salmonella spp. infection, salami was the most frequent food exposure among the pork products, even if the consumption of salami alone would not explain all S. Goldcoast cases in this outbreak.

Salami has been implicated in several Salmonellarelated food-borne outbreaks in Italy $[19,20]$ as well as other countries [21-23]. Salami are dry fermented sausages traditionally considered safe due to low $\mathrm{pH}$, 
low water activity and high salinity, but Salmonella can survive fermentation and drying steps if the manufacturing process or fermentation periods are inadequate. The main reasons for contaminated salami are Salmonella contamination at the initial manufacturing stages and/or failures during the fermentation process [24]. Observations from a recent study on the survival of Salmonella in different types of Italian salami, demonstrated that the Salmonella population declined during the experimental period but surviving organisms were always detected at the end of that period [25]. Several studies aiming at estimating the magnitude of reduction of the Salmonella population in Italian salami, using different techniques of preparation and storage conditions, have yielded varying results. A model developed by Pin et al. [26], predicted one order of magnitude reduction of the Salmonella population in salami during the storage period. Higher levels of reduction were reported by Nightingale et al. [27] and Porto-Fett et al. [28] in experimental studies in fermented and dried Italian-style and Genoa salami, respectively. Conversely, Messier et al. [29] did not detect surviving Salmonella organisms after 11 days in Genoa salami inoculated with $10^{3} \mathrm{cfu} / \mathrm{g}$. These data demonstrate that although salami manufacturing processes generally lead to appreciable reductions in the levels of Salmonella, they do not always result in a reduction of the initial pathogen loads, adequate to avoid possible transmission to human.

The delay between the occurrence of the majority of the epidemic cases and the time of the investigation, represented the most critical limitation of our study. Had both the epidemiological and microbiological investigations been conducted immediately after the peak of the outbreak in 2009, more concrete risk exposures may have been identified. The possibility of sampling and testing the suspected food items were also strongly hampered by the poor timeliness of the outbreak investigation, which limited the possibility to detect the outbreak source. Even the trace-back activity for suspected food, which can be of crucial importance for the identification of the source of infection, or at least for identifying where a contamination of the food-production chain could have occurred (e.g. preharvest or post-harvest), was limited by the difficulties of tracing back the salami. Salamis are usually made from minced meat of various species and animals (usually either pork or pork and beef) that may originate from various batches and/or carcasses. This makes the trace-back of these products, even on a small scale, extremely challenging.

These limitations of our investigation may also explain why a common link between cases of $S$. Goldcoast infection in Italy and Hungary could not be clearly established, although evidence from the molecular characterisation of $S$. Goldcoast strains and the epidemiological findings (temporal pattern connection, characteristics of the cases, suspected food) suggested an evident epidemiologic relationship between them.
In conclusion, this report shows that the outbreak of AGI associated with the rare $S$. Goldcoast serotype that occurred in Italy in 2009 and 2010 was probably part of a larger multistate outbreak with a continuous source. Our results highlight how crucial the exchange of information was, at EU, national or regional level, for both the outbreak detection and investigation. Epidemiological and microbiological information on cases, collected in a surveillance system for AGI associated with enteric pathogens, should be aimed at detecting and promptly investigating community-wide outbreaks. Whenever such data are disconnected, as in the case of Italy, it is essential to efficiently combine the information, in order to avoid delay in outbreak detection and investigation. Similarly, sharing of protocols for Salmonella spp. strain typing between human and veterinary laboratory networks is critical in order to generate and confirm hypotheses on possible sources of infection.

\section{Acknowledgements}

We thank Cinzia Ancarani, Giovanna Audano, Anna Belloni, Guglielmino Baitelli, Valentina Bellucci, Ave Bettati, Liana Boldori, Luca Casagni, Massimo Fabbi, Alba Carola Finarelli, Manuela Franchetti, Elisabeth Kanitz, Pierangela Napoli, Carla Nespoli, Rosanna Passatempo, Maria Cristina Parenti, Fabrizio Perrelli, Gabriella Pinciroli, Francesca Sambo, Simone Schmorak, Livia Trezzi, Cristina Zappetti, for their collaboration in the field outbreak investigation.

We are grateful to the Enter-net Italia and Enter-Vet surveillance networks, for supporting the laboratory investigation. We also thank Ildo Benedetti for his technical assistance in PFGE, Silvia Tagliabue and Stefania Scuota for providing S. Goldcoast strains from animals and food, and Lapo MughiniGras for his support in editing the manuscript.

Conflict of interest

None declared. 


\section{References}

1. Bremer V, Leitmeyer K, Jensen E, Metzel U, Meczulat H, Weise E, et al. Outbreak of Salmonella Goldcoast infections linked to consumption of fermented sausage, Germany 2001. Epidemiol Infect. 2004;132(5):881-7. http://dx.doi.org/10.1017/ So950268804002699. PMid:15473151. PMCid:2870175.

2. Coia J, Cormican M, Ethelberg S, Fisher I, Hernandez Pezzi G, Hjertqvist M, et al. Outbreak of Salmonella Goldcoast affecting tourists exposed in Majorca from the UK, Ireland, Sweden, Norway and Denmark. Euro Surveill. 2005;10(43):pii=2821. Available from: http://www.eurosurveillance.org/ViewArticle. aspx?Articleld=2821. PMid: 16790894 .

3. Joce R, O'Sullivan DG, Strong C, Rowe B, Hall MLM, Threlfall EJ. A national outbreak of Salmonella Goldcoast. Commun Dis Rep CDR Rev. 1990;4:3-4.

4. Threlfall EJ, Hall MLM, Rowe B. Salmonella Goldcoast from outbreaks of food-poisoning in the British Isles can be differentiated by plasmid profiles. J Hyg (Lond). 1986;97(1):11522. http://dx.doi.org/10.1017/So022172400064408

5. Report of the Task Force on Zoonoses Data Collection on the Analysis of the baseline study on the prevalence of Salmonella in holdings of laying hen flocks of Gallus gallus. EFSA Journal. 2007;97:1-84 Available from: http://www.efsa.europa.eu/en/ efsajournal/pub/97r.htm

6. Analysis of the baseline survey on the prevalence of Campylobacter in broiler batches and of Campylobacter and Salmonella on broiler carcasses in the EU, 2008, Part A: Campylobacter and Salmonella prevalence estimates. EFSA Journal. 2010;8 (03):1503. Available from: http://www.efsa. europa.eu/en/efsajournal/pub/1503.htm

7. Report of the Task Force on Zoonoses Data Collection on the Analysis of the baseline survey on the prevalence of Salmonella in turkey flocks, Part A. EFSA Journal. 2008;134:191. Available from: http://www.efsa.europa.eu/en/efsajournal/ pub/134r.htm

8. Analysis of the baseline survey on the prevalence of Salmonella in holdings with breeding pigs, in the EU, 2008, Part A: Salmonella prevalence estimates. EFSA Journal. 2009;7(12):1-93. Available from: http://www.efsa.europa.eu/ en/efsajournal/pub/1377.htm

9. Report of the Task Force on Zoonoses Data Collection on the analysis of the baseline survey on the prevalence of Salmonella in slaughter pigs, Part A. EFSA Journal. 2008;135:1-111. Available from: http://www.efsa.europa.eu/en/ efsajournal/pub/135r.htm

10. The Community Summary Report on Trends and Sources of Zoonoses, Zoonotic Agents and Food-borne Outbreaks in the European Union in 2007; EFSA Journal. 2009;223. Available from: http://www.efsa.europa.eu/en/efsajournal/doc/223r.pdf

11. The Community Summary Report on Trends and Sources of Zoonoses, Zoonotic Agents and Food-borne Outbreaks in the European Union in 2008; EFSA Journal. 2010;8:1496. Available from: http://www.efsa.europa.eu/en/efsajournal/doc/1496.pdf

12. Graziani C, Galetta P, Busani L, Dionisi AM, Filetici E, Ricci A, et al. Infezioni da Salmonella: diagnostica, epidemiologia e sorveglianza. [Salmonella infections: diagnosis, epidemiology and surveillance]. Rapporti ISTISAN. 2005;05/C27:29-32. Italian. Available from: http://www.iss.it/binary/publ/ publi/05-27.1132583099.pdf

13. Mughini-Gras L, Graziani C, Biorci F, Pavan A, Magliola R, Ricci A, et al. Surveillance of acute infectious gastroenteritis (1992-2009) and food-borne disease outbreaks (1996-2009) in Italy, with a focus on the Piedmont and Lombardy regions. Euro Surveill. 2012;17(8):pii=20098. Available from: http:// www.eurosurveillance.org/ViewArticle.aspx?Articleld=20098. PMid:22401508.

14. Threlfall EJ, Fisher IS, Berghold C, Gerner-Smidt P, Tschäpe $\mathrm{H}$, Cormican $\mathrm{M}$, et al. Antimicrobial drug resistance in isolates of Salmonella enterica from cases of salmonellosis in humans in Europe in 2000: results of international multicentre surveillance. Euro Surveill. 2003;8(2):pii=400. Available from: http://www.eurosurveillance.org/ViewArticle. aspx?Articleld $=400$

15. Ribot EM, Fair MA, Gautom R, Cameron DN, Hunter SB, Swaminathan B, et al. Standardization of pulsed-field gel electrophoresis protocols for the subtyping of Escherichia coli 0157: H7, Salmonella, and Shigella for PulseNet. Foodborne Pathog Dis. 2006; 3(1):59-67. http://dx.doi.org/10.1089/ fpd.2006.3.59. PMid:16602980.

16. Römling U, Tümmler B. Achieving $100 \%$ typeability of Pseudomonas aeruginosa by pulsed-field gel electrophoresis. J Clin Microbiol. 2000;38(1):464-5. PMid:10618146. PMCid:88754.

17. Hunter SB, Vauterin P, Lambert-Fair MA, Van Duyne MS, Kubota $\mathrm{K}$, Graves L, et al. Establishment of a universal size standard strain for use with the PulseNet standardized pulsed-field gel electrophoresis protocols: converting the national databases to the new size standard. I Clin Microbiol. 2005;43(3):104550. http://dx.doi.org/10.1128/JCM.43.3.1045-1050.2005. PMid:15750058. PMCid:1081233.

18. Scavia G, Baldinelli F, Busani L, Caprioli A. The burden of selfreported acute gastrointestinal illness in Italy: a retrospective survey, 2008-2009. Epidemiol Infect. 2012;140(7):1193-206. http://dx.doi.org/10.1017/S0950268811002020. PMid:22014077. PMCid:3365479.

19. Pontello M, Sodano L, Nastasi A, Mammina C, Astuti M, Domenichini $M$, et al. A community-based outbreak of Salmonella enterica serovar Typhimurium associated with salami consumption in Northern Italy. Epidemiol Infect. 1998;120(3):209-14. http://dx.doi.org/10.1017/ So95026889800870X. PMid:9692597. PMCid:2809396.

20. Luzzi I, Galetta P, Massari M, Rizzo C, Dionisi AM, Filetici E, et al. An Easter outbreak of Salmonella Typhimurium DT104A associated with traditional pork salami in Italy. Euro Surveill. 2007;12(4):pii=702. Available from: http:// www.eurosurveillance.org/ViewArticle.aspx?Articleld=702. PMid:17991384.

21. Cowden IM, O'Mahony M, Bartlett CL, Rana B, Smyth B, Lynch $D$, et al. A national outbreak of Salmonella Typhimurium DT124 caused by contaminated salami sticks. Epidemiol Infect. 1989;103(2):219-25. http://dx.doi.org/10.1017/ So950268800030569. PMid:2680542. PMCid:2249499.

22. Emberland KE, Nygard K, Heier BT, Aavitsland P, Lassen J, Stavnes TL, et al. Outbreak of Salmonella Kedougou in Norway associated with salami, April-June 2006. Euro Surveill. 2006;11:(27):pii=2995. Available from: http://www. eurosurveillance.org/ViewArticle.aspx?Articleld=2995. PMid:16966755.

23. Kuhn KG, Torpdahl M, Frank C, Sigsgaard K, Ethelberg S. An outbreak of Salmonella Typhimurium traced back to salami, Denmark, April to June 2010. Euro Surveill. 2011:16(19):pii=19863. Available from: http://www. eurosurveillance.org/ViewArticle.aspx?Articleld=19863. PMid:21596006.

24. Mataragas M, Skandamis PN, Drosinos EH. Risk profiles of pork and poultry meat and risk ratings of various pathogen product combinations. Int J Food Microbiol. 2008;126(1-2):1 12. http://dx.doi.org/10.1016/j.ijfoodmicro.2008.05.014 PMid:18602180.

25. Cosciani-Cunico E. Sviluppo di una banca dati per la microbiologia alimentare e validazione di modelli predittivi sulla cinetica di microorganismi patogeni in prodotti italiani a base di latte e di carne. [Database development and validation of predictive models on the kinetic responses of pathogens in Italian dairy and meat products]. PhD Thesis in Food Science and Technology. Parma: University of Parma; 2009. Italian. Available from: http://hdl.handle.net/1889/1105

26. Pin C, Avendano-Perez G, Cosciani-Cunico E, Gomez N Gounadakic A, Nychas G], et al. Modelling Salmonella concentration throughout the pork supply chain by considering growth and survival in fluctuating conditions of temperature, pH and Aw. Int J Food Microbiol. 2011;145 Suppl 1:S96-S102. http://dx.doi.org/10.1016/j.ijfoodmicro.2010.09.025. PMid:20951457

27. Nightingale KK, Thippareddi H, Phebus RK, Marsden JL Nutsch AL. Validation of a traditional Italian-style salami manufacturing process for control of Salmonella and Listeria monocytogenes. J Food Control. 2006;69(4):794-800.

28. Porto-Fett AC, Call JE, Shoyer BE, Hill DE, Pshebniski C, Cocoma Gl, et al. Evaluation of fermentation, drying, and/ or high pressure processing on variability of Listeria

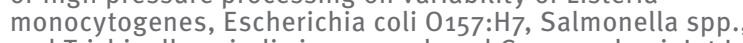
and Trichinella spiralis in raw pork and Genoa salami. Int J Food Microbiol. 2010;140(1):61-75. http://dx.doi.org/10.1016/j. ijfoodmicro.2010.02.008. PMid:20207436.

29. Messier S, Smith HJ, Tittiger F. Survival of Salmonella Typhimurium and Staphylococcus aureus in Genoa salami of varying salt concentration. Can J Vet Res. 1989;53(1):84-6. PMid:2644005. PMCid:1255519. 